IZA DP No. 7338

The Radical Innovation Investment Decision Refined

Natasa Bilkic

Thomas Gries

Wim Naudé

April 2013 


\title{
The Radical Innovation Investment Decision Refined
}

\author{
Natasa Bilkic \\ CIE, University of Paderborn \\ Thomas Gries \\ CIE, University of Paderborn \\ Wim Naudé \\ MSM, UNU-MERIT, University of Maastricht \\ and IZA
}

\section{Discussion Paper No. 7338 \\ April 2013}

IZA
P.O. Box 7240
53072 Bonn
Germany

\author{
Phone: +49-228-3894-0 \\ Fax: +49-228-3894-180 \\ E-mail: iza@iza.org
}

\begin{abstract}
Any opinions expressed here are those of the author(s) and not those of IZA. Research published in this series may include views on policy, but the institute itself takes no institutional policy positions. The IZA research network is committed to the IZA Guiding Principles of Research Integrity.
\end{abstract}

The Institute for the Study of Labor (IZA) in Bonn is a local and virtual international research center and a place of communication between science, politics and business. IZA is an independent nonprofit organization supported by Deutsche Post Foundation. The center is associated with the University of Bonn and offers a stimulating research environment through its international network, workshops and conferences, data service, project support, research visits and doctoral program. IZA engages in (i) original and internationally competitive research in all fields of labor economics, (ii) development of policy concepts, and (iii) dissemination of research results and concepts to the interested public.

IZA Discussion Papers often represent preliminary work and are circulated to encourage discussion. Citation of such a paper should account for its provisional character. A revised version may be available directly from the author. 
IZA Discussion Paper No. 7338

April 2013

\section{ABSTRACT}

\section{The Radical Innovation Investment Decision Refined}

We refine modelling of the radical innovation decision in this paper by extending real option theory to include non-marginal stochastic jump processes. From the model analytics we determine that the average magnitude and frequency of non-marginal stochastic jump processes are the most important parameters in this highly uncertain decision process. We show that these stochastic shocks imply that investment in radical innovation may very often be too time consuming and/or expensive to remain attractive for private entrepreneurs.

JEL Classification: D92, D81, L26

Keywords: radical innovation, innovation, entrepreneurship, investment, $R \& D$, risk, real option theory, technology

Corresponding author:

Wim Naudé

Maastricht School of Management

PO Box 1203

6201 BE Maastricht

The Netherlands

E-mail: naude@msm.nl 


\section{Introduction}

Radical innovation can have a dramatic and significant impact on firms and societies (Lipsey et al., 2005). Despite this, it has been less frequently studied or formalized than for instance incremental innovation (Schoenmakers and Duysters, 2010). The existing literature has focused on descriptive and empirical studies of radical innovation, and has been more concerned about commercialization post-invention, rather than on the determinants of radical innovation on a firm level (Ferriani et al., 2008; Golder et al., 2009). Although the growing literature on innovation (see e.g. Sena, 2004) has made important advances to model the innovation process it still neglects the impact of major stochastic shocks on investment in radical innovation, particularly on the decision to bring an invention to market or to continue with R\&D efforts. This is a significant omission because radical innovation, unlike incremental innovation, is more sensitive to the impact of major stochastic shocks. In this paper we contribute to addressing this shortcoming by proposing a novel method for modeling the decision to invest in radical innovation. To be specific, we propose a real options model to determine the optimal duration of $\mathrm{R} \& \mathrm{D}$ for radical innovation. Although real options models have been used to study innovation our model introduces a novel method for analyzing the effect of major stochastic shocks. The essence of our model is that we use dynamic programming to identify a trigger threshold level of profits that against the backdrop of possible major stochastic shocks can fix the timing of market entry and hence the expected duration of the $R \& D$ period and the total volume of investment.

The paper is structured as follows. In section 2 we discuss the relevant literature and argue for the appropriateness of using the real options approach to study radical innovation. In section 3 we present our model. The model's analytics are described in section 4 . Section 5 concludes.

\section{Radical Innovation and Real Option Theory}

\subsection{The Neglect of Radical Innovation}

Innovation is the 'putting into practice of inventions' (Fagerberg et al., 2005). Such inventions have often, though not exclusively, been in the form of new technologies. ${ }^{1}$ Technological innovation is an iterative process initiated by the perception of a new market and/or service opportunity for a technologybased invention which leads to development, production, and marketing for the commercial success of the invention (Garcia and Calantone, 2002: 112).

As Schumpeter $(1911 ; 1942)$ famously stressed, innovation is important for economic growth and development. Modern growth theory accords technological progress a major role in productivity growth (Aghion and Howitt, 1998). Innovation is vital for firm performance, for instance in providing entrepreneurs

\footnotetext{
${ }^{1}$ More generally innovation can include the exploitation of new markets and the development of new ways to organize business.
} 
with new products with monopoly rents or ensuring firm survival (Chandy and Tellis, 1998; Tellis et al. 2009; Bessant, 2003). Entrepreneurs play an essential role in undertaking risky innovation (Audretsch and Aldridge, 2007; Marvel and Lumpkin, 2007).

There is a substantial scientific literature on innovation, covering amongst others the theories of innovation (Freeman, 1994; Nooteboom, 2000), how to measure innovation (Freeman and Soete, 2009; Lanjouw and Schankerman, 2004), the nature of innovation (Shavinina and Seeratan, 2003; Schoenmakers and Duysters, 2010), the patterns of (technological) innovation such as the technological S-curve (Sood and Tellis, 2005); the process of innovation (Pavitt, 2005); the determinants of innovation (Tellis et al., 2009) including innovation persistence (Clausen et al., 2012); national and regional innovation systems and policies (Patel and Pavitt, 1994; Lundvall, 2007); and the impact of innovation on performance and on economies, including spillovers (Sena, 2004) and the diffusion and adoption of innovations and absorption capabilities (Fagerberg and Verspagen, 2007; Soete and Turner, 1984; Soete, 1985; Szirmai, Naudé, and Goedhuys, 2011).

Within this literature a relatively neglected topic is that of radical innovation - as distinct from most 'incremental' 2 forms of innovation (Schoenmakers and Duysters, 2010). 'Radical' innovation is also described as breakthrough', disruptive, discontinuous, game-changing or revolutionary" innovation (O'Connor and McDermott, 2004). It is often identified ex post and typical lists of radical innovations include for example the microwave oven, transistors, laser printers, the laptop computer, cellular telephone, digital camera, gyrocompass, penicillin, and oral contraceptives (Audretsch and Aldridge, 2007; Slocum and Rubin, 2008).

Investing in $R \& D$ for incremental innovations aims at the continuous (stepwise) improvement of a product, and is subject only to marginal uncertainty. By contrast, investing in $R \& D$ for radical innovation involves more fundamental uncertainty. It requires that the entrepreneurial firm undertaking these investments be willing to spend large investment flows in $\mathrm{R} \& \mathrm{D}$ over a long period, even if this fail to generate results, in the hope that this will lead to major research steps or even a breakthrough at some unpredictable future point in time. Hence, investing in $R \& D$ for radical innovations is characterized by major events (or jumps) which can be either positive or negative. While a sudden leap forward or breakthrough in research is a positive event, negative events such as a competitor announcing a launch of a substitute may substantially reduce the market value of a firm's existing research. The firm may also find that its current research has come to a dead-end. The uphot is that both positive and negative major events may cause major jumps in the expected value of $R \& D$

\footnotetext{
${ }^{2}$ According to Chandy and Tallis (1998:476) incremental innovations "involve relatively minor changes in technology and provide relatively low incremental customer benefits per dollar"; in contrast radical innovations "involve substantially new technology and [provide substantially greater customer benefits". Radical innovations are thus innovations that "could not have evolved through improvements to, and modifications of, the existing technology'(Slocum and Rubin, 2008:11).
} 
projects aimed at radical innovations. These non-marginal stochastic jumps occur in the context of the general high risks involved in radical innovation.

\subsection{The Risks of Radical Innovation}

Radical innovation is costly and complex and hence a very risky business strategy (see also Treacy, 2004). It is costly because it requires large investment flows. According to Lynn et al. (1996) it can cost more than US\$ 100 million to bring a radical innovation to market. These costs are high because radical innovations need new factories or markets before they can be exploited (Freeman, 1994:474). This is a major reason why most radical innovations are performed by large incumbent firms rather than small start-ups (Hill and Rothaermel, 2003; Ahuja and Lampert, 2001). Radical innovation is also expensive because it requires long time-spans and a long-term focus. Golder et al. (2009) studied 29 radical innovations, whose average gestation period or incubation time for radical innovations was 50 years. According to Bessant and Venables (2008: 3), "lead times between initial knowledge production and later commercialization in sectors such as these routinely exceed 10 to 15 years".

Radical innovation is complex because such $R \& D$ projects are difficult to manage. High levels of managerial, engineering, and entrepreneurial skills are required (Marvel and Lumpkin, 2007). There is often considerable internal resistance against radical innovation attempts. One reason is that a new innovation can cannibalize a firm's existing sales (Chandy and Tellis, 1998). Investors may also be locked in to earlier investment decisions on which they first want to earn a return before these are threatened by newer technologies or products.

The costs and complexity give rise to high technical uncertainty in that a breakthrough invention is not guaranteed. As Freeman (1994) notes, radical innovation requires the long accumulation of scientific knowledge. Furthermore, there is high market or commercial uncertainty since even if a breakthrough invention is made, it may not be successful commercially. Treacy (2004:2) writes that radical business models are often too radical for their markets. Whether or not an invention will be adopted by others, either consumers or other firms, depends on a number of factors, as a substantial body of literature has identified. For instance, Bhide (2008) argues that one needs consumers who are willing to experiment with buying and using new products or services. Often, a new product is dependent on the acceptance and uptake of complementary products, services or technologies that are already available; this causes uncertainty for the innovating firm because quite suddenly a complementary product can appear that will make the commercialization of its under-developed new product possible. Conversely, there is a risk that other firms will bring to market a substitute that may make a firm's own formerly radical innovation suddenly obsolete or unmarketable (e.g. Belenzon, 2012).

As a result of innovation being subject to such high risks, but also potentially lucrative if successful, many innovating firms adopt a mixed strategy where they follow a radical innovation with a series of more incremental innovations. Apple is a firm that has followed such a mixed innovation strategy. Since the radical 
innovation of the iPhone, most of Apple's innovations have been incremental innovations.

\subsection{Relevance of Real Option Theory for Radical Innova- tion}

The fact that a radical innovation project is characterized by high costs, complexity, and uncertainty, as discussed, suggests that a real options approach to investment may be useful to understand and derive rules of optimal decisionmaking. In contrast to the now-or-never decision the real option approach allows for deferring the decision about an irreversible action to a later date (Dixit and Pindyck 1994) and leads to inter-temporal optimization. Previous investigations of uncertainty in investment decisions show that real option models deliver a number of additional insights into its effect. For instance, Sakar (2000) argues that an increase in uncertainty leads a firm to invest more within a specific period while Wong (2007) shows that the investment threshold has an U-shaped pattern depending on the volatility modeled. That is, greater uncertainty may lead to a shorter waiting period and earlier investment.

Only recently have scholars started to propose R\&D models that explicitly apply analytical methods based on real options theory. For instance, Frazin et al. (1998) and Doraszelski (2001) apply real options theory ${ }^{3}$ to discuss the optimal timing of investment in technology adoption. They determine that uncertainty has an significant effect on timing. In particular, Doraszelski (2001) finds that higher uncertainty about the speed of arrival and degree of technology improvement will defer the adoption of new technology. This result changes with the introduction of technical uncertainty where the firm invests in an uncertain stock. Sakar (2000), for instance, shows that an increase in uncertainty in such a case leads the firm to invest more within a specific period. Further results for R\&D investments and innovations are provided by Jørgensen et al. (2006) and Whalley (2011). Both argue that investments in intellectual capital of a firm may drive innovations, while Whalley (2011) uses utility-based valuation to determine the certainty-equivalent value of the $\mathrm{R} \& \mathrm{D}$ project to the entrepreneur.

While the literature discussed in this section has made important advances in modelling innovation they do not take into consideration the possible impact of non-marginal stochastic shocks or jumps on the decision to invest in R\&D. Possible non-marginal stochastic jumps include sudden scientific breakthroughs or abrupt backlashes to innovations. As far as we can discern, there has not yet been an attempt in the literature to address the question of how long and how much an entrepreneur can expect to invest in R\&D in order to develop a radical invention before entering the market, particularly when the entrepreneur faces non-marginal stochastic jumps. Hence, an important question about the theory of radical innovation and in particular on modeling the timing, gestation, and duration of research and development (R\&D) investment is not considered. Sudden non-marginal stochastic jumps have, however, been studied in financial

\footnotetext{
${ }^{3}$ See Dixit (1989), Dixit (1993) and Dixit and Pindyck (1994).
} 
economics and more recently in business cycle theory. Beginning with Merton (1975) jump processes were introduced to model rare events that cause nonmarginal movements in financial values. The impact of disasters has also been modeled as simple downward jumps (e.g., Cox et al., 2000, 2004). As an extension, Yang and Zhang (2005) and Jang (2007) use a jump diffusion processes to model the randomness of disasters, that is, their unknown frequency and impact. More general jump diffusion models are presented by Pham (1997) and Kou (2002), while Kou and Wang (2003) and Cai and Kou (2011) analyze various characteristics of jump processes.

\section{The Model}

\subsection{Intuitive Description}

We start by providing an intuitive description of our model. When an (entrepreneurial) firm decides to spend on $\mathrm{R} \& \mathrm{D}$ in the hope to generate a radical innovation it faces two challenges: first to have a successful $R \& D$ outcome, i.e. an innovation; and second to successfuly commercialization of the invention, i.e. achieve a high earning period after the $R \& D$ phase. The period before market entry is characterized by pure investments in technological innovation. It is costly and long, as explained in section 2. Moreover, the costs of developing and launching a radically new product accumulate over time.

The firm needs to decide at each moment whether, and if so when, a radical innovation can be generated and successfully commercialized. That is, the present state of technical innovation and the firm's expectations could (i) trigger an immediate market entry, (ii) lead the firm to expect market entry to become profitable after a certain time, or (iii) lead the firm to expect that a market entry is no longer profitable at all. Instead of entering the market straight away, the entrepreneurial firm can defer, invest more in R\&D, and improve the technology, while still retaining the value of waiting. This may allow the market to mature and complementary technologies to be developed. Upon market entry the technical innovation process is terminated, the invention is launched, and the earning period starts. The profit flow in this period will depend on the timing of the entry, as our model shows. This is an important aspect most often neglected when considering the risks of radical innovation.

Having described the decision problem as a timing decision to enter the market, in the sections below we apply real options theory in a dynamic programming model. The decision is determined by the sequential comparison of the net present value of profits of a potential market entry with the value of postponing market entry to a possible later date. Identifying the triggering threshold, we can determine two further major characteristic elements of a continuous and long-term investment into an innovation, that is the expected time of market entry, and hence the expected duration of the research period, and the expected total volume of investment needed to succeed upon market en-

try. However, even if our sequential process accounts for these expectations the 
model illustrates that a stochastic shock will have a significant impact on the decision to bring an invention to market.

In the formalization of the model in the sub-sections below we describe four key decision elements: (i) the accumulated investment flow for radical innovation; (ii) the potential market entry profit; (iii) the profit flow after market entry; and the (iv) option value of attached to continue with R\&D efforts.

\subsection{Total Investment in Radical Innovation}

The time at which an entrepreneur perceives an opportunity to start spending on $\mathrm{R} \& \mathrm{D}$ for radical innovation is denoted as $t=0$. The $\mathrm{R} \& \mathrm{D}$ phase is unknown duration and will involve costs that will accumulate until market entry. Let Crepresent these costs, which may differ amongst firms depending on their level of innovative capacity and knowledge-creation efforts. For simplicity, these costs are constant.

Total investment in radical innovation $I(T)$ is the sum of costs of each period during the $R \& D$ phase. Denoting the end of the research period and the market entry by $T$, the current value of total investment in radical innovation at the moment of market can be denoted as follows:

$$
I(T)=\int_{0}^{T} C e^{r(T-t)} d t
$$

where $r$ is the risk-free interest rate.

\subsection{Potential Market Entry Profit}

At each moment the state of technological sophistication reached in the $R \& D$ phase is associated with a specific level of profit if the invention should be marketed. However, this profit, even if positive, may not be adequate. Hence the firm may prefer to continue with R\&D. With each additional period of not entering the market, the firm waits for another major step forward or a technical breakthrough. Hence, postponing market entry is a more profitable strategy - but not always. R\&D could produce a breakthrough, but it could also produce a failure or encounter an insurmountable technological obstacle. While the first event would lead to an upward jump in the economic value of $R \& D$, the latter would cause a downward adjustment. ${ }^{4}$ By using jump processes we are able to model a sudden success or disaster in the $R \& D$ process that may lead to strong non-marginal changes in the value of radical innovation. Large upward or downward jumps in the potential market entry profit are regarded as a stochastic shock because they represent both fundamental threats and major opportunities. We describe the development of potential market entry profits

\footnotetext{
${ }^{4}$ We neglect marginal fluctuations and consider a model of jump accumulation that focuses on major effects only. Hence this model is a variation of a model used in financial economics. For instance, Pham (1997) uses Jump-Diffusion processes to analyze options.
} 
during the $\mathrm{R} \& \mathrm{D}$ period before the new product is launched as an compound Poisson Process:

$$
d \tilde{Y}=\tilde{Y} \int_{U_{1}} u N_{1}(t, d u) \quad \text { for } \quad 0<t<T
$$

The jump part of the stochastic process is represented by the integral $\int_{U_{1}} z N_{1}(t, d z)$

where $N_{1}(t, d z)$ a Poisson Process with intensity $\lambda_{1}$. As far as we are aware, this model is the first to focus on such large uncertainties in the time path of R\&D. The model enables an accumulation of non-marginal jumps which occur at random points in time with an uncertain step height out of $U_{1}$, which is a Borel Set whose closure does not contain 0 . That is, the occurrence of a major positive or negative event is unpredictable.

\subsection{Profit Flow after Market Entry}

Once a firm decides to commercialize its invention its profits are determined by market conditions. Accordingly these profits are highly uncertain since they are subject to unforeseen events as discussed in section 2. On the one hand, sudden opportunities may open up - for instance competing entrepreneurs may exit the market or completely new markets may open up. On the other hand, negative events may dramatically worsen the market value of the innovation after market entry for instance as a result of product imitation or an apparent substitute offered by competitors. Alternatively, the market could suffer an overall economic crisis that affects aggregate demand. Hence we model profits after market entrey as a second compound Poisson Process:

$$
d Y=Y \int_{U_{2}} z N_{2}(t, d z) \quad \text { for } \quad T<t .
$$

This process allows for an accumulation of opportunities and threats through the integral $\int_{U_{2}} z N_{2}(t, d z) . N_{2}(t, d z)$ denotes a Poisson Process with intensity $\lambda_{2}$. Jumps with an uncertain step height out of $U_{2}$, which is a Borel Set whose closure does not contain 0 , occur randomly and can be downward as well as upward.

After market entry the profit stream evolves within the limits of a random process. The economic value of innovation consists solely of its future profit

stream. For a risk neutral entrepreneur the market value of research results $V^{\text {gross }}$ is determined by the expected present value of the profit stream: 


$$
\begin{aligned}
V^{\text {gross }} & =\frac{Y(T)}{\left(r-\int_{f^{-1}\left(U_{2}\right)} z v_{2}(d z)-\int_{U_{2}}[\ln (1+z)-z] v_{2}(d z)\right)} ; \\
r & >\int_{f^{-1}\left(U_{2}\right)} z v_{2}(d z)+\int_{U_{2}}[\ln (1+z)-z] v_{2}(d z),
\end{aligned}
$$

with $r$ being the risk-free interest rate. $f$ denotes the function $f(z)=\ln (1+$ $z$ ) and $v_{2}$ refers to the Lévy Measure of the Poisson Process $N_{2}$. For simplicity the entrepreneur lives forever.

In order to determine the expected net value of the new technology the expected gross value (4) has to be adjusted for the costs of innovation $I(T)$. Hence, the expected net value of innovation is the gross stream $V^{\text {gross }}$ minus investment costs:

$$
V=V^{\text {gross }}-I(T) .
$$

\subsection{Option Value of Innovation}

Even if market entry is profitable for the entrepreneur, postponing it and conducting further R\&D may be valuable. Accounting for the option value $F$ for the compound Poisson Process (2), the Hamilton-Jacobi-Bellman equation holds:

$$
r F d t=E(d F) .
$$

This equation indicates that for a time interval $d t$, the total expected return on the investment opportunity is equal to the expected rate of capital appreciation.

\section{Model Analytics: Determining the Entry De- cision and Expected Time of Market Entry}

\subsection{Expected Time of Market Entry}

An entrepreneu $r$ taking the route of radical innovation need to constantly evaluate the market value of the current state of $\mathrm{R} \& \mathrm{D} V$ and compare it with the option value $F$ of further R\&D that can lead to a technical breakthrough. The option value $F$ of postponing market entry and conducting further R\&D can be determined by applying dynamic programming and solving for

$$
\max \left\{V^{\text {gross }}(T)-I(T), F(T)\right\} .
$$

This indicates that solving for the expected time of market entry involves two steps. First, for each waiting period we need to determine the value of the required current profit level of $\mathrm{R} \& \mathrm{D}$ results (threshold $Y^{*}$ ) that would make market entry desirable. When this threshold is reached the value of current 
research exceeds the option value of more research, and potentially an even more valuable innovation. Hence, market entry becomes preferable. Second, while each moment the threshold marks the required value for market entry the entrepreneur verifies if the current pre-market entry value $\tilde{Y}$ reaches this threshold

Determining this threshold is the first part of a solution to the expected timing of market entry.

Proposition 1 For the costs of innovation I, a pre-market entry value of current profits while being innovative (2), and future profit streams after market entry following (3), we can determine the threshold $Y^{*}$ that would trigger commercialization of the innovation

$$
\begin{aligned}
Y^{*} & =\frac{\beta}{\beta-1}\left[r-\int_{f^{-1}\left(U_{2}\right)} z v_{2}(d z)-\int_{U_{2}}[\ln (1+z)-z] v_{2}(d z)\right] I(T)(7) \\
\text { with } r & >\int_{f^{-1}\left(U_{2}\right)} z v_{2}(d z)+\int_{U_{2}}[\ln (1+z)-z] v_{2}(d z)
\end{aligned}
$$

$\beta$ is an implicit function resulting from the differential equation $r F d t=E(d F)$ with solution $F=\tilde{\sim} \tilde{Y}^{\beta}$.

Proof. see Appendix 1.

The expected time at which the pre-market entry value $(\tilde{Y}))$ is expected to reach the threshold (7) and triggers market entry is referred to as the first passage time. However, since we consider compound Poisson Processes, there is overshooting that has to be taken into account. The existence of an analytical solution for the first passage time can therefore only be ensured for a small number of jump size distributions. Accordingly, we utilize the double exponential distribution as an example for which an analytical solution exists. As in Kou and Wang (2003) the double exponential distribution is given by

$$
h(z)=p \eta_{1} e^{-\eta_{1} z} 1_{\{z \geq 0\}}+q \eta_{2} e^{\eta_{2} z} 1_{\{z<0\}},
$$

where $p$ is the probability of a positive jump and $q$ of a negative jump, respectively, with $p+q=1$. $\frac{1}{\eta_{1}}$ and $\frac{1}{\eta_{2}}$ denoting the means of the two exponential distributions. These exponential distribution can be interpreted as distributions of the waiting period until a positive or negative jump occurs. In other words, in this innovation period the occurrence of fundamental opportunities and threats affects the decision to enter the market.

In order to analytically determine the first passage time, in the next section we first suggest an instrument that allows for a non-linear development of the threshold. We call this instrument the expected first-time realization of market entry profit. That is for the random process $(\tilde{Y}$ see $(2))$ we derive the expected time of first realizing or overshooting a certain market entry profit $\tilde{Y}_{i}$ (given 
today's value $\tilde{Y}_{0}$ ). By using the Girsanov Theorem we can derive the probability density function of $\tilde{T}_{i}{ }^{5}$, which is sometimes referred to as the Inverse Gaussian Distribution. ${ }^{6}$ As we can determine the expected time of first realizing or overshooting of each value of the strictly monotonic increasing sequence $\tilde{Y}_{i} \in\left\{\tilde{Y}_{1}, \tilde{Y}_{2}, \ldots, \tilde{Y}_{n}\right\}$ with $0=\tilde{Y}_{1} \leq \tilde{Y}_{2} \leq \ldots \leq \tilde{Y}_{n}$ and $\tilde{Y}_{1}>\tilde{Y}_{0}$ we can write the expected first realization or overshooting time as a function of $\tilde{Y}_{i}$ and of the overall drift of the jump process $\bar{u}=\lambda_{1}\left(\frac{p}{\eta_{1}}-\frac{q}{\eta_{2}}\right)$.

Proposition 2 Using the compound Poisson Process (2) we can derive the expected time of first realization or overshooting E $\tilde{T}$ of each market profit $\tilde{Y}_{i} \in$ $\left\{\tilde{Y}_{1}, \tilde{Y}_{2}, \ldots, \tilde{Y}_{n}\right\}$ with $0=\tilde{Y}_{1} \leq \tilde{Y}_{2} \leq \ldots \leq \tilde{Y}_{n}$ and $\tilde{Y}_{1}>\tilde{Y}_{0}$ as a function of $\tilde{Y}_{i}$, and hence determine the expected time until any market entry profit $\tilde{Y}$ is reached for the first time as:

$$
E(\tilde{T})=\frac{1}{\bar{u}}\left[\tilde{Y}_{i}+\frac{\mu_{2}^{*}-\eta_{1}}{\eta_{1} \mu_{2}^{*}}\left(1-e^{-Y^{*} \mu_{2}^{*}}\right)\right] .
$$

$\bar{u}$ refers to the overall drift $\bar{u}=\lambda_{1}\left(\frac{p}{\eta_{1}}-\frac{q}{\eta_{2}}\right)$ of the jump process and $\mu_{2}^{*}$ is a constant derived in the technical note, for which $0<\eta_{1}<\mu_{2}^{*}<\infty$ holds.

Proof. see Appendix 1.

Hence, to determine the first passage time $T^{*}$ we have to compare all points $\left(\tilde{Y}_{i}, E\left(\tilde{T}, \tilde{Y}_{i}\right)\right)$ and $\left(Y_{i}, T\right)$ from the sets of the threshold as well as from the $E T_{i}$ curve and choose the point that is included in both sets. The resulting $T^{*}$ determines the first passage time. As the image set of $E T_{i}$ is a sequence there may be no exact match with the threshold curve. In this case we choose the first point in time for which the threshold curve lies above the $\mathrm{ET}_{i}$ curve, that is $T(Y)>E\left(\tilde{T}, \tilde{Y}_{i}\right){ }^{7}$ The next proposition provides conditions for the existence of the first passage time.

Proposition 3 With the threshold $Y^{*}(T)$ (see (9)), the expected first-time realization of initial market profit $E \tilde{T}$ (see (8)), and condition (10) and (11) there exists an expected time to enter the market $T^{*}=E(T)>0 . T^{*}$ is the first time point for which the following conditions hold:

$$
T^{*}(Y) \geq E\left(\tilde{T}, \tilde{Y}_{i}\right) .
$$

\footnotetext{
${ }^{5}$ An extensive discussion is offered by Karatzas and Shreve (1991, p.196) and Karlin and Taylor $(1975$, p.363).

${ }^{6}$ The term "Inverse Gaussian Distribution" stems from the inverse relationship between the cumulant generating functions of these distributions and those of the Gaussian distributions. For a detailed discussion of the inverse Gaussian distribution see Johnson, Kotz, and Balakrishnan (1995) or Dixit (1993).

${ }^{7}$ As in Dixit and Pindyck ((1994), page 160$)$ the curves F,V-I have an upward slope. However, under certain conditions they can also decrease because in this model costs are accumulated. For details see technical Note 3.
} 


$$
\begin{aligned}
\frac{1}{r} \ln \frac{\tilde{Y}_{1}+K C}{K C} & <\frac{1}{\bar{u}}\left[\tilde{Y}_{1}+\frac{\mu_{2}^{*}-\eta_{1}}{\eta_{1} \mu_{2}^{*}}\left(1-e^{-\tilde{Y}_{1} \mu_{2}^{*}}\right)\right] \\
\frac{1}{r} \ln \frac{\left(\tilde{Y}_{t}+K C\right)\left(\tilde{Y}_{i}+K C\right)}{\left(\tilde{Y}_{s}+K C\right)\left(\tilde{Y}_{j}+K C\right)} & <\frac{1}{\bar{u}}\left[\begin{array}{c}
\tilde{Y}_{t}+\tilde{Y}_{i}-\tilde{Y}_{s}-\tilde{Y}_{j} \\
+\frac{\mu_{2}^{*}-\eta_{1}}{\eta_{1} \mu_{2}^{*}}\left(e^{-\tilde{Y}_{s} \mu_{2}^{*}}+e^{-\tilde{Y}_{j} \mu_{2}^{*}}\right. \\
\left.-e^{-\tilde{Y}_{t} \mu_{2}^{*}}-e^{-\tilde{Y}_{i} \mu_{2}^{*}}\right)
\end{array}\right]
\end{aligned}
$$

with $K=\frac{\beta}{\beta-1}\left(r-\int_{f^{-1}\left(U_{2}\right)} z v_{2}(d z)-\int_{U_{2}}[\ln (1+z)-z] v_{2}(d z)-\alpha\right)$.

Proof. See Appendix 1.

The existence of the expected time of market entry $T^{*}$ indicates that from today's perspective the entrepreneur can expect to realize a later market entry and hence it is beneficial to invest in the project. A threshold that is higher than the expected initial market profit reflects that innovation costs during the research phase (before $T^{*}$ ) and the value of irreversibly enter the market are not yet sufficiently compensated by the current value of R\&D. In addition, condition (10) is important to understand the logic of the decision problem. ${ }^{8}$ The decision in favor of initiating a research process for a certain time will only be positive if the minimum profit is sufficiently small compared to the R\&D costs at the beginning, and that the time path of the research value can be expected to hit the profit threshold as the result of the research activity. ${ }^{9}$

Further, $T^{*}$ indicates the expected duration of research under present conditions. $T^{*}$ is the answer to the question of how long an entrepreneur can expect to invest in R\&D. Second, with $T^{*}$ the entrepreneur can also determine their expected total investment volume $I\left(T^{*}\right)$.

\subsection{Determinants of Expected Time of Market Entry}

In the previous sections we showed that high uncertainty or stochastic shocks, and irreversibility, are important ingredients of radical innovation. In this section we provide a closer examination of the effects of such stochastic shocks on radical innovation. In particular, we consder the frequency of jumps and the effect of the jump-size during the innovation period where we can already identify a market entry but when the entrepreneur has not yet decided to commercialize.

Proposition 4 An increase in the frequency of sudden breakthroughs or backlashes during the RESD period is generally ambiguous. However, an increase in $\lambda_{1}$ may lead to an earlier market entry $E T^{*}$ if $\frac{p}{\eta_{1}}-\frac{q}{\eta_{2}}>0,1<\frac{\mu_{2}^{*}-\eta_{1}}{\eta_{1}} e^{-Y^{*} \mu_{2}^{*}}$ and the sum of upward jumps is sufficiently large to outweigh of the sum of

\footnotetext{
${ }^{8}$ Both conditions are required for the existence of a solution to the problem.

${ }^{9}$ This condition is required for the time path of the threshold curve which is below the time path of the market entry profit curve.
} 
negative jumps so that $\frac{\partial \beta}{\partial \lambda_{1}}<0$.

$$
\begin{aligned}
& \frac{\partial E\left(T^{*}\right)}{\partial \lambda_{1}}=-\frac{\left(\frac{p}{\eta_{1}}-\frac{q}{\eta_{2}}\right)}{\left[\lambda_{1}\left(\frac{p}{\eta_{1}}-\frac{q}{\eta_{2}}\right)\right]^{2}}\left[Y^{*}+\frac{\mu_{2}^{*}-\eta_{1}}{\eta_{1} \mu_{2}^{*}}\left(1-e^{\left.-Y^{*} \mu_{2}^{*}\right)}\right]\right. \\
& +\frac{1}{\lambda_{1}\left(\frac{p}{\eta_{1}}-\frac{q}{\eta_{2}}\right)}\left[\begin{array}{c}
-\frac{\frac{\partial \beta}{\partial \lambda_{1}}}{(\beta-1)^{2}}\left(r-\int_{f^{-1}\left(U_{2}\right)} z v(d z)\right. \\
\left.-\int_{U_{2}}[\ln (1+z)] v_{2}(d z)\right)
\end{array}\right] \\
& \cdot\left(1-\frac{\mu_{2}^{*}-\eta_{1}}{\eta_{1}} e^{-Y^{*} \mu_{2}^{*}}\right)<0 \text {. }
\end{aligned}
$$

Proof. see Appendix 2.

The conditions $\frac{p}{\eta_{1}}-\frac{q}{\eta_{2}}>0$ and $1<\frac{\mu_{2}^{*}-\eta_{1}}{\eta_{1}} e^{-Y^{*} \mu_{2}^{*}}$ are connected to the probabilities of sudden breakthroughs or backlashes and the mean waiting times until an event occurs. The decision whether to enter the market if the frequency of jumps increases strongly depends on the direction of those jumps and therefore whether a sudden breakthrough or a backlash happens. In general, an increase in $\lambda_{1}$ in implies that more fundamental events are occurring that imply non-marginal changes in the expected path of technical findings and the associated profits. Hence, sudden positive discoveries become more frequent and the increase in the value of research results accelerates.

Proposition 5 An increase in the magnitude of breakthroughs or backlashes during the REDD period is generally ambiguous. However, an increase in u leads to an earlier market entry if $\frac{p}{\eta_{1}}-\frac{q}{\eta_{2}}>0,1<\frac{\mu_{2}^{*}-\eta_{1}}{\eta_{1}} e^{-Y^{*} \mu_{2}^{*}}$ and the sum of upward jumps is sufficiently large to outweigh of the sum of downward jumps so that $\frac{\partial \beta}{\partial u}<0$.

$\frac{\partial E\left(T^{*}\right)}{\partial u}=\frac{\left(1-\frac{\mu_{2}^{*}-\eta_{1}}{\eta_{1}} e^{-Y^{*} \mu_{2}^{*}}\right)}{\lambda_{1}\left(\frac{p}{\eta_{1}}-\frac{q}{\eta_{2}}\right)}\left[\frac{-\frac{\partial \beta}{\partial u}}{(\beta-1)^{2}}\left(\begin{array}{c}r-\int_{f^{-1}\left(U_{2}\right)} z v(d z) \\ -\int_{U_{2}}[\ln (1+z)-z] v_{2}(d z)\end{array}\right) I(T)\right]<0$.

Proof. See Appendix 2.

An increase in $u$ means that breakthroughs become more beneficial and threats less disastrous. Larger upward jumps suggest that research steps are larger up to a sudden immediate breakthrough and hence a successful market entry can be expected earlier. Hence, discoveries become more important and have a larger impact, with just one new research result potentially producing the final invention needed to successfully enter the market.

While the above two effects consider large uncertain events during the phase of research, the following two effects look at large uncertain events after market entry and show reflect the impact of these high market uncertainties on the investment decision. An example of such highly uncertain events could be a sudden emergence of close technical substitutes, a negative shock. An example of a positive shock after market entry is the transferability of the new technology to an additional and previously unconsidered market. 
Proposition 6 An increase in the frequency of sudden breakthroughs or backlashes after the market entry is generally ambiguous. However, an increase in $\lambda_{2}$ may lead to an earlier market entry $E T^{*}$ if $\frac{p}{\eta_{1}}-\frac{q}{\eta_{2}}>0, \frac{\mu_{2}^{*}-\eta_{1}}{\eta_{1}} e^{-Y^{*} \mu_{2}^{*}}>1$ and the sum of upward jumps is sufficiently large to outweigh the sum of negative jumps.

$\frac{\partial E\left(T^{*}\right)}{\partial \lambda_{2}}=\frac{1}{\lambda_{1}\left(\frac{p}{\eta_{1}}-\frac{q}{\eta_{2}}\right)}\left[\frac{\beta}{\beta-1}\left(\begin{array}{c}-\int_{f^{-1}\left(U_{2}\right)} z h(d z) \\ -\int_{U_{2}}[\ln (1+z)-z] h(d z)\end{array}\right) I(T)\right]\left(1-\frac{\mu_{2}^{*}-\eta_{1}}{\eta_{1}} e^{-Y^{*} \mu_{2}^{*}}\right)>0$.

Proof. See Appendix 2.

As discussed in the Appendix the sign of the derivative according to $\lambda_{2}$ is ambiguous. However, we assume that breakthroughs are frequent and large enough to outweigh the sum of backlashes such that a fast market entry will be preferred. More positive jumps indicate that more breakthroughs than threats and losses can be expected after market entry. Having invented a new product and launched it on the market, new information may show up additional and unexpected applications for this product. Upon market entry, information about the new product will spread, potentially enabling the entrepreneur to enter markets in fields he never thought of before. An increasing frequency of such opportunities makes market entry more attractive, so the entrepreneur would try to enter the market with the first viable prototype.

Proposition 7 An increase in the magnitude of breakthroughs and backlashes after the market entry is ambiguous. However, an increase in $z$ leads to an earlier market entry if $\frac{p}{\eta_{1}}-\frac{q}{\eta_{2}}>0, \frac{\mu_{2}^{*}-\eta_{1}}{\eta_{1}} e^{-Y^{*} \mu_{2}^{*}}>1$ and the sum of upward jumps is sufficiently large to outweigh the sum of downward jumps.

$\frac{\partial E\left(T^{*}\right)}{\partial z}=\frac{1}{\lambda\left(\frac{p}{\eta_{1}}-\frac{q}{\eta_{2}}\right)}\left[\begin{array}{c}-\frac{\beta}{\beta-1}\left(\int_{>0} 1 v_{2}(d z)\right. \\ \left.+\int_{U_{2}}\left[\frac{1}{(1+z)}-1\right] v_{2}(d z)\right) \underbrace{I(T)}_{>0}\end{array}\right]\left(1-\frac{\mu_{2}^{*}-\eta_{1}}{\eta_{1}} e^{-Y^{*} \mu_{2}^{*}}\right)<0$

Proof. See Appendix 2.

An increase in $z$ indicates that opportunities become more beneficial and threats less disastrous. Larger upward jumps imply that the benefits from opportunities provided by market entry increase. At the same time, smaller downward jumps reduce the loss in profits generated by threats. Hence, opportunities are more beneficial than threats so that market entry is expected to have a greater payoff. We observe that further $R \& D$ becomes less attractive because the existing prototype, even if not perfect, promises such comercialization success that an earlier market entry is preferred.

From the model analytics described in this section we can conclude that stochastic shocks have a determining impact on the radical innovation investment decision. The extent of R\&D may be prolonged or terminated depending on such stochastic events. 


\section{Concluding Remarks}

Entrepreneurial firms need to take strategic decisions with respect to radical innovations that take into account their sequential nature, their magniture, and their fundamental uncertainty. In particular, what makes radical innovation different from incremental innovation is that its success is much more dependent on the occurrence (or not) of certain stochastic events, which can be both positive and negative, but in essence unpredictable. Hence, the key strategic decisions for an entrepreneurial firm that wishes to be a successful radical innovator will be a) how much to invest in $R \& D$ and $b$ ) when to bring the innovation to market, i.e., when to enter the market.

In this paper we presented a real options model to derive the optimal entry timing and show that stochastic jumps - especially the direction and intensity of jumps - affect both adical innovation investment behavior and market entry. Our contribution lies in extending the real options theory with respect to entrepreneurial innovation decisions by introducing non-marginal stochastic jump processes to discuss the effects of such large uncertain events on these decisions. From the model analytics we determine that the average magnitude of these sudden events as well as the direction (up or down) and frequency of the associated jumps are the most important parameters in this highly uncertain decision process.

However, as we can also endogenously determine the expected investment time and the underlying value of investment flows into the research program for radical innovations, total value and time horizon do matter. These stochastic shocks imply that investment in radical innovation may very often be too time consuming and/or expensive to remain attractive for private entrepreneurs.

\section{References}

[1] Aghion, P. and Howitt, (1998). Endogenous Growth Theory. MIT Press.

[2] Ahuja, G. and Lampert, C.M. (2001). 'Entrepreneurship in The Large Corporation: A Longitudinal Study of How Established Firms Create Breakthrough Inventions', Strategic Management Journal, 22 : 521-543.

[3] Applebaum, D. (2009). Levy Processes and Stochastic Calculus. Cambridge University Press, 2nd Edition.

[4] Audretsch, D. and Aldridge, T. (2007). 'Radical Innovation', Interim Report to Anders Hoffman, FORA: Danish Authority for Enterprise and Construction.

[5] Belenzon, S. (2012). 'Cumulative Innovation and Market Value: Evidence from Patent Citations', The Economic Journal, 122 (559): 265-285. 
[6] Bessant, J. (2003). 'Challenges in Innovation Management', (In Shavinina, L. ed. The International Handbook on Innovation. Oxford: Elsevier Science).

[7] Bessant, J. and Venables, T. eds. (2008). Creating Wealth from Knowledge: Meeting the Innovation Challenge. Cheltenham: Edward Elgar.

[8] Bhide, A. (2008). The Venturesome Economy. Princeton: Princeton University Press.

[9] Cai, N. and Kou, S.G. (2011). 'Option Pricing Under a Mixed-Exponential Jump Diffusion Model, Management Science, 57 (11) : 2067-2081.

[10] Chandy, R.K. and Tellis, G.J. (1998). 'Organizing for Radical product Innovation: The Overlooked Role of Willingness to Cannibalize', Journal of Marketing Research, 35: 474-487.

[11] Clausen, T., Pohjola, M., Sapprasent, K. and Verspagen, B. (2012). 'Innovation Strategies as a Source of Persistent Innovation', Industrial and Corporate Change, 21 (3): 553-585.

[12] Cox, H.; Fairchild, J. and Pedersen, H. (2004). 'Valuation of Structured Risk Management Products ', Insurance, Mathematics and Economics, 34, 259-272.

[13] Cox, S.H.and Pedersen, H. (2000). 'Catastrophe Risk Bonds', North American Actuarial Journal, 4(4), 56-82.

[14] Dixit, A.K. (1989). 'Entry and Exit Decisions under Uncertainty', Journal of Political Economy, 97 (3): 620-638.

[15] Dixit, A.K. (1993). The Art of Smooth Pasting. Chur, Switzerland: Harwood Academic Publishers.

[16] Dixit, A.K. and Pindyck, R.S. (1994). Investment under Uncertainty. Princeton University Press.

[17] Doraszelski, U. (2001). 'The Net Present Value Method versus the Option Value of Waiting: A Note on Farzin, Huisman and Kort (1998) ', Journal of Economic Dynamics \&3 Control, 25: 1109-1115.

[18] Fagerberg, J. and Verspagen, B. (2007). 'Innovation, growth and economic development: have the conditions for catch-up changed?', International Journal of Technological Learning, Innovation and Development, 1(1) : 1333.

[19] Fagerberg, J., Mowery, D.C. and Nelson, R.R. (2005). The Oxford Handbook of Innovation. Oxford: Oxford University Press.

[20] Farzin, Y.H.; Huismann, K.J.M. and Kort, P.M. (1998). 'Optimal Timing of Technology Adaption', Journal of Dynamics \&3 Control, 22: 779-799. 
[21] Ferriani, S. Probert D. and Garnsey, E. (2008). Sustaining Breakthrough Innovation in Large Established Firms: Learning Traps and Counteracting Strategies (In Bessant, J. and Venables, T. eds. Creating Wealth from Knowledge: Meeting the Innovation Challenge. Cheltenham: Edward Elgar.)

[22] Freeman, C. (1994). 'The Economics of Technical Change', Cambridge Journal of Economics, 18: 463-514.

[23] Freeman, C. and Soete, L. (2009). 'Developing science, Technology and Innovation Indicators: What we can learn from the Past', Research Policy, 38 (4): $583-589$

[24] Fudenberg, D., Tirole J., Gilbert R. and Stiglitz, J. (1983). 'Preemption, Leapfrogging, and Competition in Patent Races ', European Economic Review, 22: 3-31.

[25] Garcia, R. and Calantone, R. (2002). 'A Critical Look at Technological Innovation Typology and Innovativeness Terminology: A Literature Review', Journal of Product Innovation Management, 19: 110-132.

[26] Golder, P.N., Shacham, R. \& Mitra, D. (2009).'When, By Whom, and How Are Radical Innovations Developed?', Marketing Science, 28(1): 166-179.

[27] Hill, C.W.L. and Rothaermel, F.T. (2003). 'The Performance of Incumbent Firms in the Face of Radical Technological Innovation', Academy of Management Review, 28(2): 257-274.

[28] Jang, J. (2007). 'Jump Diffusion Processes and their Applications in Insurance and Finance', Insurance, Mathematics and Economics 41: 62-70.

[29] Johnson, N. L.; Kotz, S. and Balakrishnan, N. (1995). Continuous Univariate Distributions. 2nd Edition, New York: John Wiley \& Sons, Inc.

[30] Jørgensen, S., Kort, P. M. and Dockner, E. J. (2006). 'Venture Capital financed Investments in Intellectual Capital,' Journal of Dynamics $\& 3$ Control, 30: 2339-2361.

[31] Karatzas and Shreve (1996). Brownian Motion and Stochastic Calculus. Springer.

[32] Karlin, S. and Taylor, H.M. (1975). First Course in Stochastic Processes. Academic Press.

[33] Kou, S.G. (2002). 'A Jump-Diffusion Model for Option Pricing', Management Science, 48 (8): 1086-1101.

[34] Kou, S.G. and Wang, H. (2003). 'First Passage Time of a Jump Diffusion Process', Advances in Applied Probability, 35 (2): 504-531. 
[35] Lanjouw, J. and Schankerman, M. (2004). 'Patent Quality and Research Productivity: Measuring Innovation with Multiple Indicators', The Economic Journal, 114 (495): 441-465.

[36] Leifer, R.C. and McDermott, M. O'Connor, G. Peters, L.S, Rice, M.P. and Veryzer, R.W. (2000). Radical Innovation: How Mature Companies can Outsmart Upstarts. Boston: Harvard Business School Press.

[37] Lipsey, R.G., K.I. Carlaw and C.T. Bekar (2005). Economic Transformations: General Purpose Technologies and Long-Term Economic Growth. Oxford: Oxford University Press.

[38] Lundvall, B-A. (2007). 'National Innovation Systems-Analytical Concept and Development Tool', Industry and Innovation, 14 (1): 95-119.

[39] Marvel, M.R. and Lumpkin, G.T. (20087). 'Technology Entrepreneurs' Human Capital and Its Effects on Innovation Radicalness', Entrepreneurship Theory and Practice, November : $807-828$.

[40] McDonald, R.; and Siegel, D. (1986). The Value of Waiting to Invest, Quarterly Journal of Economics, November : 707-729.

[41] Merton, R.C. (1976). Option Pricing when the Stock Returns are Discontinuous, Journal of Financial Economics, 3: 125-144.

[42] Nooteboom. B. (2000). Learning and Innovation in Organizations and Economies. Oxford: Oxford University Press.

[43] O'Connor, G. and McDermott, C.M. (2004).'The Human Side of Radical Innovation', Journal of Engineering and Technology Management, 21 : 1130 .

[44] Patel, P. and Pavitt, K. (1994). 'National Innovation Systems: Why They Are Important and How They Might be Measured and Compared', Economics of Innovation and New Technology, 3 (1): 77-95.

[45] Pavitt, K. (2005). The Process of Innovation (In Fagerberg, J., Mowery, D.C. and Nelson, R.R. eds. The Oxford Handbook of Innovation. Oxford: Oxford University Press.)

[46] Pham, H. (1997). 'Optimal Stopping, Free Boundary, and American Option in a Jump-Diffusion Model', Applied Mathematics and Optimization, 35: $145-164$.

[47] Sarkar, S. (2000). 'On the Investment-Uncertainty Relationship in a Real Options Model', Journal of Economic Dynamics and Control, 24: 219-225.

[48] Schoenmakers, W. and Duysters, G. (2010). 'The Technological Origins of Radical Innovations', Research Policy, 39: 1051-1059. 
[49] Schumpeter, J.A. (1911). The Theory of Economic Development. Cambridge, MA: Harvard University Press, 1934 (1911).

[50] Schumpeter, J.A.(1943). Capitalism, Socialism and Democracy. London, Allen and Unwin, 1976 (1943).

[51] Sena, V. (2004). 'The Return of the Prince of Denmark: A Survey on Recent Developments in the Economics of Innovation', The Economic Journal, 114 (496): F312-332.

[52] Shavinina, L. and Seerantan, K. L. (2003). 'On the Nature of Individual Innovation' (In Shavinina, L. ed. The International Handbook on Innovation. Oxford: Elsevier Science).

[53] Slocum, A. and Rubin, E.S. (2008). 'Understanding Radical Technology Innovation and its Application to C02 Capture R\&D', Paper 66, Department of Engineering and Public Policy, Carnegie Institute of Technology.

[54] Soete, L. (1985). 'International Diffusion of Technology, Industrial Development and Technological Leapfrogging', World Development, 13 (3): 409 -422 .

[55] Soete, L. and Turner, R. (1984). 'Technology Diffusion and the Rate of Technical Change', The Economic Journal, 94: 612-623.

[56] Sood, A. and Tellis, G.J. (2005). 'Technological Evolution and Radical Innovation', Journal of Marketing, 69: 152-158.

[57] Szirmai, A., Naudé, W.A., and Goedhuys, M. eds. (2011). Entrepreneurship, Innovation and Economic Development. Oxford: Oxford University Press.

[58] Tellis, G.J., Prabhu, J. C. and Chandy R. K. (2009). 'Radical Innovation across Nations: The Preeminence of Corporate Culture', Journal of Marketing, 73 (1): 3-23.

[59] Treacy, M. (2004). 'Innovation as a Last Resort', Harvard Business Review, July - August : $1-2$.

[60] Whalley, A.E. (2011). 'Optimal R\&D Investment for a Risk-Averse Entrepreneur', Journal of Economic Dynamics 83 Control, 35, 413-429.

[61] Wong, K.P. (2007). 'The Effect of Uncertainty on Investment Timing in a Real Option Model', Journal of Economic Dynamics 83 Control, 31: 21532167.

[62] Yang, H.; Zhang, L. (2005). 'Optimal Investment for Insurers with JumpDiffusion Risk Process', Insurance: Mathematics and Economics, 37, 615634. 


\section{Appendix 1: Expected Time of Market Entry}

Proof of Proposition 1. Apply the boundary conditions

$$
\begin{aligned}
F(0) & =0 \\
F\left(Y^{*}\right) & =V^{\text {gross }}\left(Y^{*}\right)-I \quad \text { value matching condition, } \\
\frac{d F\left(Y^{*}\right)}{d Y} & =\frac{d\left(V^{\text {gross }}\left(Y^{*}\right)-I\right)}{d Y} \quad \text { smooth pasting condition. }
\end{aligned}
$$

and solve the equation system for $Y^{*}$.

Proof of Proposition 2. For a jump process the first passage problem can be solved analytically if we assume an explicit distribution of the jump sizes. Following Kou and Wang (2003)we assume the double exponential distribution

$$
h(z)=p \eta_{1} e^{-\eta_{1} z} 1_{\{z \geq 0\}}+q \eta_{2} e^{\eta_{2} z} 1_{\{z<0\}},
$$

where $p$ is the probability of a positive jump and $q$ for a negative, respectively. $\frac{1}{\eta_{1}}$ and $\frac{1}{\eta_{2}}$ are the means of the two exponential distributions. The moment generating function for $\tilde{Y}(t)$ with $\theta \in\left(-\eta_{2}, \eta_{1}\right)$ is

$$
\phi(\theta, t):=E\left(e^{\theta \tilde{Y}(t)}\right)=\exp (G(\theta) t)
$$

where the function $G$ is defined as

$$
G(x):=\lambda_{1}\left(\frac{p \eta_{1}}{\eta_{1}-x}+\frac{p \eta_{2}}{\eta_{2}+x}-1\right) .
$$

For jump processes the study of first passage times has to consider the exact hit of a constant boundary as well as an overshoot. Accordingly, two cases have to be distinguished. The Laplace transformation of the first hitting time, which is when $\tilde{Y}(t)$ hits the boundary $Y^{*}$ exactly, ${ }^{10}$ is :

$$
E\left(e^{-\varepsilon \tilde{T}_{i}} 1_{\left\{\tilde{Y}\left(\tilde{T}_{i}\right)=Y^{*}\right\}}\right)=\frac{\eta_{1}-\beta_{1, \varepsilon}}{\beta_{2, \varepsilon}-\beta_{1, \varepsilon}} e^{-Y^{*} \beta_{1, \varepsilon}}+\frac{\beta_{2, \varepsilon}-\eta_{1}}{\beta_{2, \varepsilon}-\beta_{1, \varepsilon}} e^{-Y^{*} \beta_{2, \varepsilon}}
$$

with $\mu_{1, \varepsilon}$ and $\mu_{2, \varepsilon}$ being the only positive roots of $G(\beta)=\varepsilon$ and $0<\beta_{1, \varepsilon}<$ $\eta_{1}<\beta_{2, \varepsilon}<\infty$. For every overshoot $\tilde{Y}(\tilde{T})-Y^{*}$ the Laplace transformation is

$E\left(e^{-\varepsilon \tilde{T}} 1_{\left\{\tilde{Y}\left(\tilde{T}_{i}\right)-Y^{*}>y\right\}}\right)=e^{-\eta_{1} y} \frac{\left(\eta_{1}-\mu_{1, \varepsilon}\right)\left(\mu_{2, \varepsilon}-\eta_{1}\right)}{\eta_{1}\left(\mu_{2, \varepsilon}-\mu_{1, \varepsilon}\right)}\left(e^{-Y^{*} \mu_{1, \varepsilon}}-e^{-Y^{*} \mu_{2, \varepsilon}}\right)$ for all $y \geq 0$.

The expectation of the first passage time is finite, i.e. $E\left(T^{*}\right)<\infty$, if and only if the overall drift of the jump process is positive. Hence,

$$
E\left(T^{*}\right)<\infty \Leftrightarrow \bar{u}=\lambda_{1}\left(\frac{p}{\eta_{1}}-\frac{q}{\eta_{2}}\right)>0 .
$$

\footnotetext{
${ }^{10}$ See Kou and Wang (2003), Theorem 3.1.
} 
Now for $\bar{u}>0$ we determine the first passage time as

$$
E\left(T^{*}\right)=\frac{1}{\bar{u}}\left[Y^{*}+\frac{\mu_{2}^{*}-\eta_{1}}{\eta_{1} \mu_{2}^{*}}\left(1-e^{-Y^{*} \mu_{2}^{*}}\right)\right]
$$

where $\mu_{2}^{*}$ is defined as the unique root of $G\left(\mu_{2}^{*}\right)=0$ with $0<\eta_{1}<\mu_{2}^{*}<\infty$.

Proof of Proposition 3. For each $\tilde{Y}_{i}$ we can determine the corresponding expected time $E\left(\tilde{T}_{i}\right)$ when this market entry profit $\tilde{Y}_{i}$ is reached for the first time. In order to find the expected time of market entry we have to consider all combinations of profit levels $\tilde{Y}_{i}$ (and, $Y_{i}$ respectively) and the required time to reach this level $E\left(\tilde{T}_{i}\right)\left(T_{i}\right.$, respectively) from the first passage time and the threshold function. That is, we compare the image sets of those functions and choose the point in time which refers to the exact hit or overshoot of the threshold as the expected time of market entry. Now we provide a sketch of the proof for the existence of this point. However, assume that $\tilde{Y}_{i}$ is an element of the strictly monotonic increasing sequence $\left\{\tilde{Y}_{0}, \tilde{Y}_{1}, \ldots, \tilde{Y}_{n}\right\}$ with $0=\tilde{Y}_{0} \leq \tilde{Y}_{1} \leq \ldots \leq \tilde{Y}_{n}$, so that $E(\tilde{T})$ can be written as a function of any $\tilde{Y}_{i}$. In this case $E\left(\tilde{T}, \tilde{Y}_{i}\right)$ is a strictly monotonic increasing sequence as well, and all pairs of values $\left(\tilde{Y}_{i}, E\left(\tilde{T}, \tilde{Y}_{i}\right)\right)$ form its image set. In order to derive the expected time before market entry, which is the time at which $\tilde{Y}$ reaches the time-dependent threshold $Y^{*}$ for the first time, we have to prove that there exists a point $\left(\tilde{Y}_{i}, E\left(\tilde{T}, \tilde{Y}_{i}\right)\right)$ which is also in the image set of the function $T(Y)$. $T(Y)$ is determined by the threshold curve

$$
\begin{gathered}
Y^{*}(T)=\underbrace{\frac{\beta}{\beta-1}\left(r-\int_{f^{-1}\left(U_{2}\right)} z v_{2}(d z)-\int_{U_{2}}[\ln (1+z)-z] v_{2}(d z)-\alpha\right)}_{=: K} C\left(e^{r T}-1\right) \\
=K C\left(e^{r T}-1\right)=K C e^{r T}-K C \\
\Rightarrow T^{*}(Y)=\frac{1}{r} \ln \frac{Y+K C}{K C} .
\end{gathered}
$$

The proof is as follows. We analyze the functions $E\left(\tilde{T}, \tilde{Y}_{i}\right)$ and $T(Y)$ near the origin and show that one function lies above the other. Next we can show that although both curves increase, the increasing rate of one function decreases faster, leading to a image point which may be in both image sets. Hence, we consider the two functions in 0 .

$$
T(0)=\frac{1}{r} \ln \frac{0+K C}{K C}=0
$$

and

$$
E(\tilde{T}, 0)=\frac{1}{\bar{u}}\left[0+\frac{\mu_{2}^{*}-\eta_{1}}{\eta_{1} \mu_{2}^{*}}\left(1-e^{-0 \mu_{2}^{*}}\right)\right]=0 .
$$

As both functions start in 0 we consider their increment of growth between 0 
and $\tilde{Y}_{1}$.

$$
\begin{gathered}
\frac{\frac{1}{r} \ln \frac{\tilde{Y}_{1}+K C}{K C}-\frac{1}{r} \ln \frac{0+K C}{K C}}{\tilde{Y}_{1}} \\
=\frac{\frac{1}{r} \ln \frac{\tilde{Y}_{1}+K C}{K C}}{\tilde{Y}_{1}} \\
=\frac{\frac{1}{\bar{u}}\left[\tilde{Y}_{1}+\frac{\mu_{2}^{*}-\eta_{1}}{\eta_{1} \mu_{2}^{*}}\left(1-e^{-\tilde{Y}_{1} \mu_{2}^{*}}\right)\right]-\frac{1}{\bar{u}}\left[\tilde{Y}_{1}+\frac{\mu_{2}^{*}-\eta_{1}}{\eta_{1} \mu_{2}^{*}}\left(1-e^{-\tilde{Y}_{1} \mu_{2}^{*}}\right)\right]}{\tilde{Y}_{1}} \\
=\frac{\frac{1}{\bar{u}}\left[\tilde{Y}_{1}+\frac{\mu_{2}^{*}-\eta_{1}}{\eta_{1} \mu_{2}^{*}}\left(1-e^{-\tilde{Y}_{1} \mu_{2}^{*}}\right)\right]}{\tilde{Y}_{1}} .
\end{gathered}
$$

The increment of growth of $T(Y)$ is smaller than the increment of growth of $E(\tilde{T}, Y)$ for

$$
\frac{1}{r} \ln \frac{\tilde{Y}_{1}+K C}{K C}<\frac{1}{\bar{u}}\left[\tilde{Y}_{1}+\frac{\mu_{2}^{*}-\eta_{1}}{\eta_{1} \mu_{2}^{*}}\left(1-e^{-\tilde{Y}_{1} \mu_{2}^{*}}\right)\right] .
$$

Furthermore, we analyze the change in the increments of growth with the second difference quotient. For any $\tilde{Y}_{i}, \tilde{Y}_{j}, \tilde{Y}_{s}, \tilde{Y}_{t}$ with $\tilde{Y}_{i}<\tilde{Y}_{j}<\tilde{Y}_{s}<\tilde{Y}_{t}$ and $\tilde{Y}_{i} \neq 0$ the second difference quotient is

$$
\begin{aligned}
& \frac{\frac{1}{r} \ln \frac{\tilde{Y}_{t}+K C}{K C}-\frac{1}{r} \ln \frac{\tilde{Y}_{s}+K C}{K C}-\frac{1}{r} \ln \frac{\tilde{Y}_{j}+K C}{K C}+\frac{1}{r} \ln \frac{\tilde{Y}_{i}+K C}{K C}}{\tilde{Y}_{t}-\tilde{Y}_{i}} \\
= & \frac{\frac{1}{r} \ln \frac{\tilde{Y}_{t}+K C}{\tilde{Y}_{s}+K C}-\frac{1}{r} \ln \frac{\tilde{Y}_{j}+K C}{\tilde{Y}_{i}+K C}}{\tilde{Y}_{t}-\tilde{Y}_{i}} \\
= & \frac{\frac{1}{r} \ln \frac{\left(\tilde{Y}_{t}+K C\right)\left(\tilde{Y}_{i}+K C\right)}{\left(\tilde{Y}_{s}+K C\right)\left(\tilde{Y}_{j}+K C\right)}}{\tilde{Y}_{t}-\tilde{Y}_{i}}
\end{aligned}
$$

and

$$
\begin{aligned}
& \frac{1}{\bar{u}}\left[\tilde{Y}_{t}+\frac{\mu_{2}^{*}-\eta_{1}}{\eta_{1} \mu_{2}^{*}}\left(1-e^{-\tilde{Y}_{t} \mu_{2}^{*}}\right)\right]-\frac{1}{\bar{u}}\left[\tilde{Y}_{s}+\frac{\mu_{2}^{*}-\eta_{1}}{\eta_{1} \mu_{2}^{*}}\left(1-e^{-\tilde{Y}_{s} \mu_{2}^{*}}\right)\right] \\
& \frac{-\frac{1}{\bar{u}}\left[\tilde{Y}_{j}+\frac{\mu_{2}^{*}-\eta_{1}}{\eta_{1} \mu_{2}^{*}}\left(1-e^{-\tilde{Y}_{j} \mu_{2}^{*}}\right)\right]-\frac{1}{\bar{u}}\left[\tilde{Y}_{i}+\frac{\mu_{2}^{*}-\eta_{1}}{\eta_{1} \mu_{2}^{*}}\left(1-e^{-\tilde{Y}_{i} \mu_{2}^{*}}\right)\right]}{\tilde{Y}_{t}-\tilde{Y}_{i}} \\
& \tilde{Y}_{t}-\tilde{Y}_{i} \\
& =\frac{\frac{1}{\bar{u}}\left[\tilde{Y}_{t}-\tilde{Y}_{s}+\frac{\mu_{2}^{*}-\eta_{1}}{\eta_{1} \mu_{2}^{*}}\left(e^{-\tilde{Y}_{s} \mu_{2}^{*}}-e^{-\tilde{Y}_{t} \mu_{2}^{*}}\right)\right]-\frac{1}{\bar{u}}\left[\tilde{Y}_{j}-\tilde{Y}_{i}+\frac{\mu_{2}^{*}-\eta_{1}}{\eta_{1} \mu_{2}^{*}}\left(e^{-\tilde{Y}_{i} \mu_{2}^{*}}-e^{-\tilde{Y}_{j} \mu_{2}^{*}}\right)\right]}{\tilde{Y}_{t}-\tilde{Y}_{i}} \\
& =\frac{\frac{1}{\bar{u}}\left[\tilde{Y}_{t}+\tilde{Y}_{i}-\tilde{Y}_{s}-\tilde{Y}_{j}+\frac{\mu_{2}^{*}-\eta_{1}}{\eta_{1} \mu_{2}^{*}}\left(e^{-\tilde{Y}_{s} \mu_{2}^{*}}+e^{-\tilde{Y}_{j} \mu_{2}^{*}}-e^{-\tilde{Y}_{t} \mu_{2}^{*}}-e^{-\tilde{Y}_{i} \mu_{2}^{*}}\right)\right]}{\tilde{Y}_{t}-\tilde{Y}_{i}} .
\end{aligned}
$$


The function $T$ increases more slowly than the sequence of $\mathrm{E}(\mathrm{T})$ for

$$
\frac{1}{r} \ln \frac{\left(\tilde{Y}_{t}+K C\right)\left(\tilde{Y}_{i}+K C\right)}{\left(\tilde{Y}_{s}+K C\right)\left(\tilde{Y}_{j}+K C\right)}<\frac{1}{\bar{u}}\left[\tilde{Y}_{t}+\tilde{Y}_{i}-\tilde{Y}_{s}-\tilde{Y}_{j}+\frac{\mu_{2}^{*}-\eta_{1}}{\eta_{1} \mu_{2}^{*}}\left(e^{-\tilde{Y}_{s} \mu_{2}^{*}}+e^{-\tilde{Y}_{j} \mu_{2}^{*}}-e^{-\tilde{Y}_{t} \mu_{2}^{*}}-e^{-\tilde{Y}_{i} \mu_{2}^{*}}\right)\right] .
$$

\section{Appendix 2: Derivatives of the Expected First Time Real- ization of Market Entry Profit Level:}

\section{Proof of Proposition 4.}

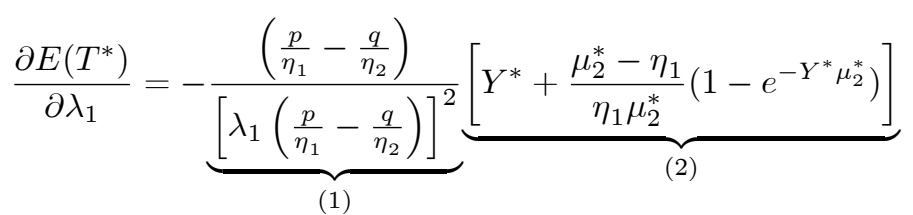

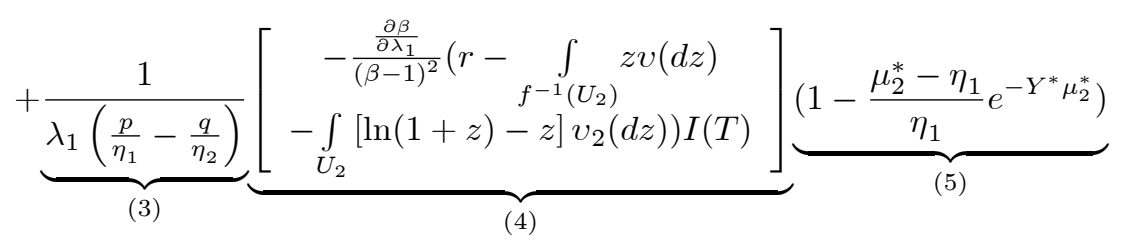

For the first term (1) we obtain

$$
\frac{\left(\frac{p}{\eta_{1}}-\frac{q}{\eta_{2}}\right)}{\left[\delta+\lambda_{1}\left(\frac{p}{\eta_{1}}-\frac{q}{\eta_{2}}\right)\right]^{2}}>0 \Leftrightarrow \frac{p}{\eta_{1}}-\frac{q}{\eta_{2}}>0 \text { with } q=1-p .
$$

With the same condition, we obtain a positive sign also for term (3)

$$
\frac{1}{\delta+\lambda_{1}\left(\frac{p}{\eta_{1}}-\frac{q}{\eta_{2}}\right)}>0
$$

For the second term (2) it holds that

$$
\underbrace{Y^{*}}_{>0}+\underbrace{\frac{\mu_{2}^{*}-\eta_{1}}{\eta_{1} \mu_{2}^{*}}}_{>0} \underbrace{\left(1-e^{-Y^{*} \mu_{2}^{*}}\right)}_{\geq 0}>0
$$

The sign of the fourth term (4) depends on whether $\frac{\partial \beta}{\partial \lambda_{1}}$ is positive or negative.

Assuming $\frac{\partial \beta}{\partial \lambda_{1}}<0$, then term (4) becomes

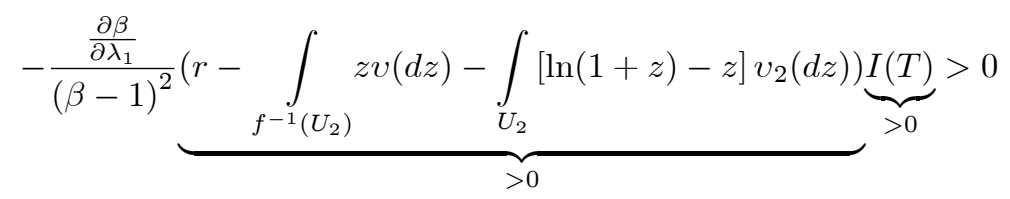


The last term (5)

$$
1-\frac{\mu_{2}^{*}-\eta_{1}}{\eta_{1}} e^{-Y^{*} \mu_{2}^{*}}
$$

is negative if

$$
1<\frac{\mu_{2}^{*}-\eta_{1}}{\eta_{1}} e^{-Y^{*} \mu_{2}^{*}}
$$

Summarizing all conditions leads to $\frac{\partial E\left(T^{*}\right)}{\partial \lambda_{1}}<0$.

Proof of Proposition 5.

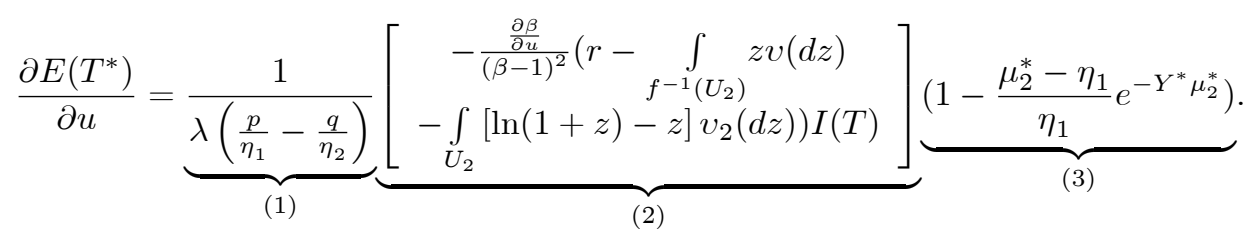

As before, the term (1) is positive. Accordingly, the last component (3) is nega-

tive for $1<\frac{\mu_{2}^{*}-\eta_{1}}{\eta_{1}} e^{-Y^{*} \mu_{2}^{*}}$. The sign of (2) depends on whether $\frac{\partial \beta}{\partial u} \gtrless 0$. Assuming that $\frac{\partial \beta}{\partial u}<0$, it follows that $\frac{\partial E(\tilde{T})}{\partial u}<0$.

Proof of Proposition 6.

$\frac{\partial E\left(T^{*}\right)}{\partial \lambda_{2}}=\underbrace{\frac{1}{\lambda_{1}\left(\frac{p}{\eta_{1}}-\frac{q}{\eta_{2}}\right)}}_{(1)} \underbrace{[\underbrace{\frac{\beta}{\beta-1}}_{>0}\left(\begin{array}{c}-\int_{f^{-1}\left(U_{2}\right)} z h(d z) \\ -\int_{U_{2}}[\ln (1+z)-z] h(d z)\end{array}\right) \underbrace{I(T)}_{>0}]}_{(2)} \underbrace{\left(1-\frac{\mu_{2}^{*}-\eta_{1}}{\eta_{1}} e^{-Y^{*} \mu_{2}^{*}}\right)}_{(3)}$.

From the conditions above (1) is positive and (3) is negative. Hence, the sign of $\frac{\partial E\left(T^{*}\right)}{\partial \lambda_{2}}$ depends on the second term and especially on the sign of $-\int_{f^{-1}\left(U_{2}\right)} z h(d z)-\int_{U_{2}}[\ln (1+z)-z] h(d z)$. Assuming more negative than positive jumps lead to a positive sign.

\section{Proof of Proposition 7.}

$$
\frac{\partial E\left(T^{*}\right)}{\partial z}=\underbrace{\frac{1}{\lambda\left(\frac{p}{\eta_{1}}-\frac{q}{\eta_{2}}\right)}}_{(>0)} \underbrace{\left[\begin{array}{c}
-\frac{\beta}{\beta-1}\left(\int_{>0} \int_{f^{-1}} 1 v_{2}(d z)\right. \\
\left.+\int_{U_{2}}\left[\frac{1}{(1+z)}-1\right] v_{2}(d z)\right) \underbrace{I(T)}_{>0}
\end{array}\right]}_{(2)} \underbrace{\left(1-\frac{\mu_{2}^{*}-\eta_{1}}{\eta_{1}} e^{-Y^{*} \mu_{2}^{*}}\right)}_{(<0)}
$$

According to the above assumptions (1) is positive and (3) is negative. The second term again depends on the jump part. However, even if there are more negative than positive jumps the effect on the jump part is not so large as to result in a negative sign. Therefore the sign of the overall derivative is negative. 